\title{
Tensile Behaviour of Friction Stir Welded Joints of Different Aluminium Alloys
}

\section{DOI : 10.36909/jer.ICCEMME.15693}

\author{
Chaitanya Sharma ${ }^{1}$, Vikas Upadhyay ${ }^{2}$, Vijay Verma ${ }^{3 *}$ Ajay Tripathi ${ }^{4}$ Sumit Sharma $^{1}$ \\ ${ }^{1}$ BIT, Sindri Dhanbad, Jharkhand, India-828123 \\ ${ }^{2}$ National Institute of Technology Patna, Patna, India-800005 \\ ${ }^{3}$ Bundelkhand Institute of Engineering and Technology, Jhansi, Jhansi-284128, India \\ ${ }^{4}$ Government Engineering College, Raipur-492001, India \\ * Corresponding Author: vijay020180@gmail.com
}

\begin{abstract}
This paper investigates the outcome of base metals and their temper condition on tensile and fracture behavior of friction stir welds of various work and precipitation hardening aluminium alloys in different tempers (AA1100-O, 5052-H, AA5086-O \& H25, AA2024-O \& T6, and AA6061-T651). The type and temper of aluminium alloys affected the tensile, and fracture behavior of weld joints. The extent of improvement in tensile properties of welded joints increased with a decrease in hardness (i.e., from T6 or H to O) of base metals. Softening was not observed for welded joints when base metal was in an annealed temper and an opposite trend was observed for hardened tempers ' $\mathrm{H}$ ' and ' $\mathrm{T} 6$ '. Fracture location moved towards the weld centre with the change in temper from ' $\mathrm{O}$ ' to ' $\mathrm{H}$ ' and ' $\mathrm{T} 6$ ', hardness minima were closer to base metal hardness in the first case than later. The mode of fracture was ductile for all the weld joints except AA2024-T6 and AA 6061-T651. Except for AA2024-T6 and AA 6061T651, all weld joints had ductile fracture mode.
\end{abstract}

Keywords: Welding, aluminum alloys, hardness, fracture locations, fractography.

\section{INTRODUCTION}

High specific strength, excellent cryogenic and corrosion properties are the major factor which make aluminum and its alloys more suitable material for engineering structure (Mandal, 2005). However, joining of aluminum and its alloy (viz. 2024, 2219, 5086, 6061, 
6082 and 7020, 7039, 7050, 7075, etc.) is difficult by fusion welding due to high oxidation and high thermal conductivity (Hassan et al.,2003). Solid-state, hot shear autogenous friction stir welding (FSW) process reduces problems linked to fusion welding of aluminum alloys as generated maximum temperature of about $450{ }^{\circ} \mathrm{C}$ was significantly low then melting temperature of base metal. It offers several benefits like improved joint properties and fatigue life, reduced residual stresses and distortion, higher versatility, etc., and is being increasingly used in place of riveting and fusion welding (Threadgill et al., 2009).

Literature review revealed that various aspects of work hardening and precipitation hardening aluminium alloy welded joints like material flow (Reynolds, 2000, Guerra, 2003), microstructure and mechanical behaviour (Sato et al, 2001, Lim et al. 2005, Sharma et al., 2013, Mahoney et al., 1998), process parameters (Sharma et al., 2012, Peel et al., 2003), fatigue (Sharma et al., 2014, Uemastu et al., 2009) and corrosion behaviour (Wadeson et al., 2006, Jariyaboon et al., 2009) have been reported but only a few studies discussed fracture behaviour of FSW joints (Lim et al., 2005, Sharma et al., 2013, Mahoney et al., 1998, Sharma et al., 2012, Sato et al., 1999, Liu et al., 2003a, Liu et al., 2003b, Srivatsan et al., 2007, Strobeck et al., 1999, Henz 2002). Moreover, some studies require more explanation (Mahoney et al. 1998, Srivatsan et al., 2007, Strobeck et al., 1999) of results and some contradict each other (Sato et al., 1999, Henz 2002). Mahoney et al., 1998, Strombeck et al, 1999 and Henz 2002 all reported that fracture of FSW joints during tensile examination occurred in location of minimum hardness lying in heat-affected zone (HAZ) without mentioning that whether the fracture was occurred on the advancing or retreating side of the joint. Yan et al., 2009 reported, post-weld aging after FSW of AA7050 in W temper may alter fracture place from HAZ - WNZ resulting enhancement in tensile behavior than welding in T62 or T7451. According to Chen et al., 2006, the state of the base metal has a significant impact on defect, weld shape, tensile, and fracture behaviour. While fracture in AA2219-O joints was on the advancing side of either in base metal or in WNZ. Aydin et al., 2009 performed FSW of AA2024 in different heat-treatment process and reported that during 
tensile test welded joints fractured from base metal, WNZ, or from WNZ-TMAZ interface on advancing side of the joints produced from AA2024 base metal in O, W, T4 and T6 HT process. Liu et al., 2006 observed the fracture of AA2219-T6 weld joints through HAZ on retreating side while Feng et al., 2006 observed that fracture AA2219-O weld joints from the base metal. Lin et al., 2018 carried out the FSW of AA7055 in T4 and T6 temper. They reported that T4 welds exhibited higher yield and tensile strength, and ductility in comparison to T6 welds. Zhao et al., 2020 planned a way for the prediction of tensile properties using welding heat input determined from weld input variables in FSW of AA6063.

Fracture position is an indirect indicator of the joint's weakest portion, and a thorough research is necessary to understand and improve the joint's performance. Furthermore, a comparison of the fracture positions of welds made of various types of aluminum alloys in state of various temper will aid in understanding the impact of FSW on their tensile and fracture behavior. Therefore, aluminum alloys AA1100, AA5052-H, AA5086-O and H25, AA2024-O and T6, AA6061-T651 were selected as base metals and subsequently FSWed using optimized process parameters to investigate the influence of base metal type (viz. solution or precipitation hardening) and temper (viz. annealed $\mathrm{O}$, peak hardened $\mathrm{T} 6$ or $\mathrm{H}$ and hardened T4) on tensile and fracture behavior of FSW joints.

\section{MATERIAL AND EXPERIMENTAL METHOD}

FSW was performed on Milling Machine (HMT Machine Tools India, Vertical), along rolling/extrusion direction holding plates in square butt joint configuration in a specially fabricated fixture. Pilot experiments was conducted by changing tool traverse and rpm of the spindle in speed range of $19-190 \mathrm{~mm} / \mathrm{min}$ and $410-635 \mathrm{rpm}$ to obtain defect-free joints using a die steel tool of $18 \mathrm{~mm}$ and $7 \mathrm{~mm}$ shoulder and pin (straight \& unthreaded) diameter respectively. As seen in macrographs in Fig. 1, developed joints had unfilled sections, tunnel defects, cracks, and flash, which could have been caused by turbulent flow due to excessive heat input. 

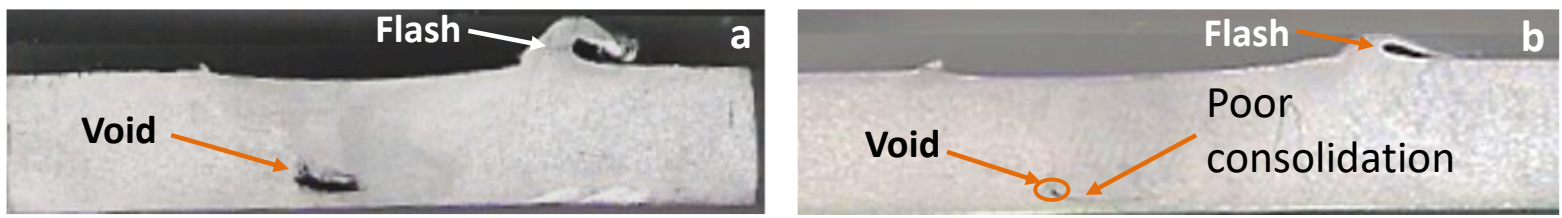

Figure 1. Defects in FSW weld joints (a) tunnel defect (b) void and poor consolidation

Therefore, tools were redesigned with smaller shoulder and pin diameters to reduce the heat generation and were used to select tool dimensions and process parameters for the main experiments as enlisted in Table 1.

Table 1. Friction stir welding process and tool parameters

\begin{tabular}{|c|c|c|c|c|c|c|c|c|}
\hline \multicolumn{4}{|c|}{ Tool dimensions (mm) } & \multicolumn{2}{|c|}{ Base metal } & \multicolumn{3}{|c|}{ Welding parameters } \\
\hline \multirow{2}{*}{$\begin{array}{l}\text { Shoulder } \\
\text { diameter }\end{array}$} & \multicolumn{2}{|c|}{ Pin diameter } & \multirow{2}{*}{$\begin{array}{c}\text { Pin } \\
\text { length }\end{array}$} & \multirow{2}{*}{$\begin{array}{c}\text { Thickness } \\
\text { (mm) }\end{array}$} & \multirow{2}{*}{$\begin{array}{l}\text { Alloy } \\
\text { Name }\end{array}$} & \multirow{2}{*}{$\begin{array}{c}\text { Welding } \\
\text { speed } \\
(\mathrm{mm} / \mathrm{s})\end{array}$} & \multirow{2}{*}{$\begin{array}{l}\text { Rotary } \\
\text { Speed } \\
\text { (rpm) }\end{array}$} & \multirow{2}{*}{$\begin{array}{c}\text { Tool } \\
\text { Tilt } \\
\left(^{0}\right)\end{array}$} \\
\hline & Top & Bottom & & & & & & \\
\hline 15 & 6 & 4 & 5.7 & 6 & AA1100 & 45 & & \\
\hline 16 & 6 & 4 & 4.7 & 5 & AA2024 & 75 & & \\
\hline 12 & & 4 & 2.7 & 3 & AA5052 & 30 & 635 & 2.5 \\
\hline 17 & 7 & 5 & 5.7 & 6 & AA5086 & 75 & & \\
\hline 12 & & 3 & 1.7 & 2 & AA6061 & 150 & & \\
\hline
\end{tabular}

ASTM E8M/E8M-21 standard was used to machine samples for tensile tests. On an average three tensile tests at $1 \mathrm{~mm} / \mathrm{min}$ crosshead speed were done on computerized universal testing machine (H25K-S, Tinius Olsen, UK). Microhardness test was performed on Walter UHL, Germany microhardness tester VHM-002V at $1 \mathrm{~N}$ load and was 30 second dwell time. Etching of the polished joints was done by Keller's reagent and then the surface was viewed under Leica, Germany (DMI500 M) optical microscope. The different aluminum alloy was etched for varying time i.e. AA1100 and AA2024 for the 30s, AA5052, and AA5086 for the 120s and AA6061 for the 90s to reveal the microstructural feature. Fractured surfaces of tensile test samples were viewed by an FE-SEM (FEI-Quanta 200®, ThermoFisher Scientific, USA) for determining fracture mode.

\section{RESULTS AND DISCUSSION}




\section{MICROHARDNESS}

The microhardness along the transverse cross-section of weld joints was evaluated to discuss the influence of FSW on weld joint's tensile strength and fracture locations. The microhardness profiles of joints are shown in Fig.2.
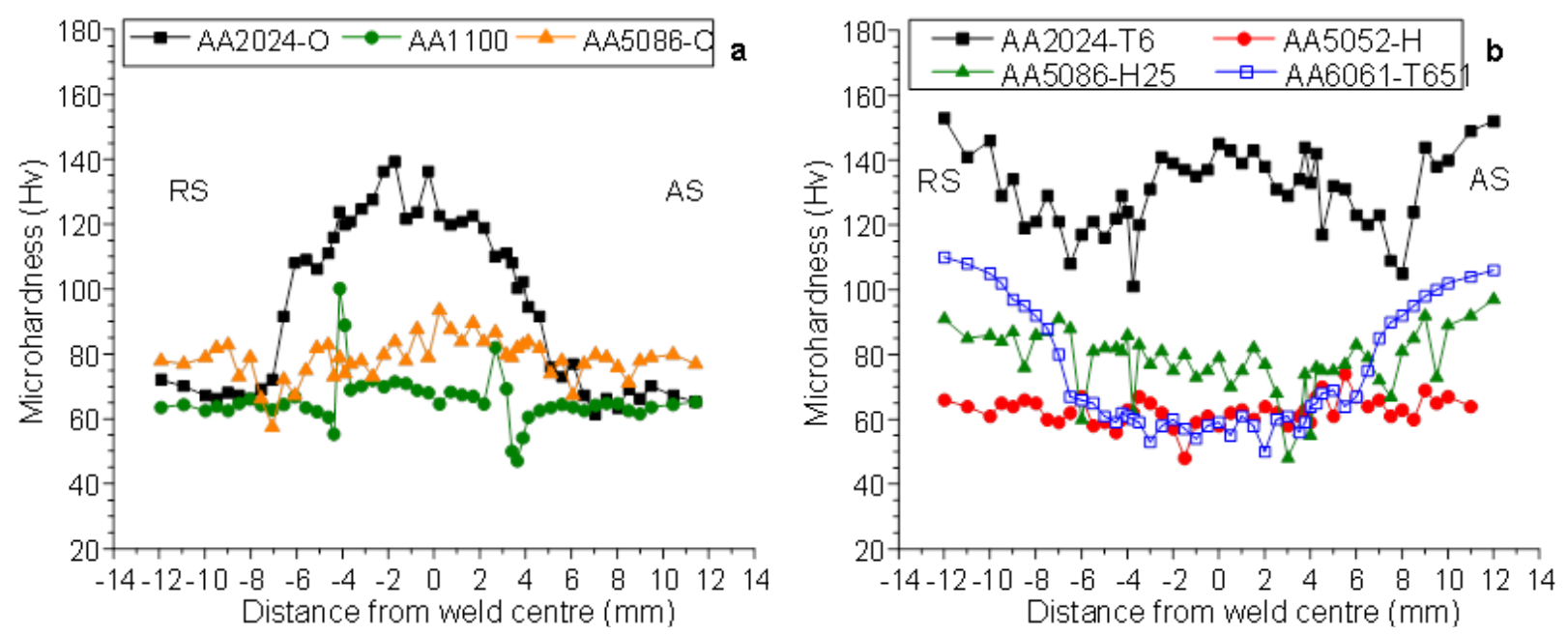

Figure 2. Microhardness profile for aluminum alloys FSW in (a) annealed O and (b) hardened $\mathrm{T} 6$ or $\mathrm{H}$ temper conditions

FSW of AL alloys in annealed O HT condition caused significant strengthening of the WNZs as evident from Fig. 7a. The average microhardness of WNZs was 63.5, 121.3, and 78.6 HV for the weld joints of AA1100-O, AA2024-O, and AA5086-O aluminum alloys, respectively. The WNZs microhardness was evaluated as higher than the respective base metals. The hardness minima were found either in HAZ or base metal, either on advancing or retreating side of weld joints, respectively. Values of hardness minima were 41, 56, and $52 \mathrm{HV}$ for the weld joints produced using AA1100-O, AA2024-O, and AA5086-O aluminum alloys respectively. FSW of AL alloys having T6 or H, HT condition developed a softened region comprising HAZ, TMAZ, and WNZ as seen in Fig. 2b. As a result, the weld joints' microhardness/ tensile strength was much lower than the base metal. WNZs average microhardness were 137.5, 59.2, 73.8, and 57.2 HV for the weld joints of AA2024-T6, AA5052-H, AA5086-H25, and AA6061-T651 respectively, and was considerably lesser than the respective base metals. The hardness minima were located in the WNZ of the weld joints 
except for AA2024-T6 which shows hardness minima at retreating side interface of TMAZWNZ. The values of hardness minima were 101, 57, 48, and $50 \mathrm{HV}$ for the weld joints produced using AA2024-T6, AA5052-H, AA5086-H25, and AA6061-T651aluminium alloys respectively. It is evident from the hardness profiles that base metal condition affected the microhardness distribution and the FSW process strengthened weld joints of aluminum alloys in the annealed condition and exhibit opposite behavior for hardened aluminum alloys. The aluminum alloys in annealed condition cannot be further softened by the heat of welding i.e., a defect-free weld joint must exhibit hardness at least equal to base metal. After FSW, weld's increased microhardness of solution hardening aluminum alloys is because of two reasons a) fine grain structure and, b) strain hardening due to plastic deformation in WNZ. As per the Hall-Patch equation, finer grains result in higher hardness/material's strength. Sato et al., 2001 attributed the increase of hardness in stir zone of friction stir welded AA1080-O to fine recrystallized grain structure and higher dislocation density than the base metal. As a result, the slope $(\mathrm{kH})$ of the Hall-Patch equation for friction-stir welds falls somewhere between annealed and ultrafine-grained aluminum alloys.

During FSW of 2017A-T451 and 7075-T651 the stable $\eta$ phase of 7075 is dissolved completely and S phase of 2017A was dissolved incompletely. Cooling, resulted in the reprecipitation of Guinier-Preston (GP) and Guinier-Preston-Bagaryatsky (GPB) zones which in turn recovered the hardness of the weld. However, hardness recovery was skewed toward the 7075-side of the weld owing to thoroughly mixed $\eta$ phase in 7075 than another alloy (Hamilton et al., 2018). In case of precipitation hardening aluminum alloys (PHAA) AA2024 and AA6061, available temperatures in WNZ are sufficient to dissolve the strengthening particles. Re-precipitation is believed to produce fine strengthening particles however, the strengthening particles which survived the heat of the welding cycle undergo coarsening, which may result in a greater population of coarsened ' $\boldsymbol{\beta}$ ' phase strengthening particles for AA6061 Welds. The re-precipitation of strengthening precipitates owing to post-weld aging is 
believed to be mainly responsible for an increased weld hardness of PHAA AA2024 welded in annealed 'O' and 'T6' condition. Similar, results were observed by other authors for friction stir welding AA6063 alloy (Sato et al., 1999). More level of hardness recovery suggests a small extent of coarsening of ' $\theta$ ' phase particles and seems to be significantly less than AA6061 Welds.

The loss of strength i.e., softening of weld joints of hardened aluminum alloys welded in the hardened condition is because of a) loss of hardening effect for solution hardening alloys, strengthening precipitate's b) dissolution in WNZ and, c) overaging in HAZ. It is well known that during FSW, WNZ is solutionized and strengthening precipitates were dissolved. Though the HAZ was not subjected to any mechanical deformation still the available temperature is high enough to provoke artificial aging leaving behind fewer severely coarsened strengthening precipitates. Weld joints in hardened aluminum alloys weaken due to the loss of hardening action and the dissolution/coarsening of strengthening precipitates. The weld heat cycle encourages consistent re-precipitation of fine precipitates, which strengthens PHAA's welds. The increase in hardness of solution hardening aluminum alloys is attributable to fine grain structure and strain hardening. Recrystallization results in fine structure which also contributes to weld's strength according to the Hall-Patch equation, i.e., finer the grains, higher the hardness, or strength, of the material.

\section{TENSILE PROPERTIES}

Transverse tensile specimens containing all the zones were used to obtain the weld's tensile properties. FSW had significant impact on the achieved tensile characteristics of welded joints for all base metal temper conditions, regardless of the hardening mechanism. O-HT condition of base material result in higher tensile strength of FSW welded joint. Whereas H or T6 HT condition of base material offers lower tensile properties of FSW welded joint. In the case of welds produced from work hardening aluminum alloys (AA1100, AA5086) in annealed O temper condition tensile strength was greater than base metal and that for precipitation 
hardening aluminum alloys AA2024 in annealed O-HT state was approximately equal as that of base metal. For example, AA1100 weld joints exhibited a tensile strength of $203 \mathrm{MPa}$, approximately $14.4 \%$ higher than the base metal whose tensile strength was only $177.7 \mathrm{MPa}$. On the other hand, welds of AA2024-O exhibited a tensile strength of $216.3 \mathrm{MPa}$ which was approximately equal to their base metal strength i.e., 222.7 MPa.

The FSW joints produced from aluminum alloys in hardened temper condition (T6 and H) exhibited tensile strength significantly lesser than the base metal. AA5052-H FSW joints showed a tensile strength of $186.2 \mathrm{MPa}$ that is approximately $11.9 \%$ lower than the base metal (211.4 MPa). FSW joints of AA6061-T651 also showed a tensile strength of 210.4 MPa which was expressively lower (30.2\%) than the base metal (301.5 MPa). The extent of the decrease in tensile strength was less in the case of work hardening aluminum alloys. Similarly, weld's tensile strength and elongation varied with plate thickness. Thick plates offered higher tensile strength and elongation than thin plates. This may be due to severe softening observed by the thin plate owing to more uniform temperature than thick plates. The decrease in yield strength $(6.7-47.4 \%)$ of the FSW joints was more severe than the ultimate tensile strength $(1.8-30.2 \%)$ of welded joints. Moreover, the extent of decrease in yield strength was found to be more in the case of hardened base metals (T651, T6, and H25 tempers) than other soft metals (in $\mathrm{O}$ temper). Also, a reduction in yield strength was found more severe in precipitation-hardened aluminum alloys (24-30.2\%) than work-hardened (11.9-22.2\%) aluminum alloys.

Invariably, all the FSW joints exhibited significantly lower percentage elongation (11.4$76.8 \%$ ) at fracture than the base metal except that produced from AA2024-O which showed higher \% elongation (33.6\%) than the base metal. Here, it should be noted that alloy AA2024 was welded in the annealed condition (i.e., saturated with secondary phase) and the higher temperature generated during FSW, accelerate the uniform re-precipitation of fine strengthening precipitate. Thus, homogeneous microstructure comprising fine recrystallized grains and strengthening precipitates may be responsible for increased ductility of AA2024-O 
weld joints (Hassan et al., 2003). The extent of reduction in percentage elongation was less in O temper condition (22.2-32.5\%) than in T651, T6, and $\mathrm{H} 25$ (15.5-76.8\%) temper conditions of the base metals. Moreover, same was more severe in the case of precipitation-hardened alloys (42.5-76.8\%) than in work-hardened (22.2-32.5\%) aluminum alloys.

Tensile (TSE) and yield (YSE) strength efficiency, ratio of corresponding weld's strength to the corresponding base material strength. Similarly, ratio of \%elongation of welded joint to base material was termed as elongation efficiency (EE). The effect of base metal temper on joint efficiencies is presented in Fig 3. The tensile strength efficiency was maximum (114.4\%) for AA1100 joints and was minimum (69.8\%) for AA6061-T651 joints. The maximum and minimum yield strength efficiency was observed for weld joints of AA5086-O (110\%) and AA5052-H (52.6\%) respectively. The elongation efficiency of AA2024-O weld joints was highest (133.6\%) whereas that of AA6061-T651 was lowest (57.5\%). It is evident that aluminum alloy type and temper affected FSW weld tensile properties significantly and the extent of improvement in tensile properties of weld joints increased with lessening in the hardness of base metals i.e., change in temper from hardened (T6 and $\mathrm{H})$ to annealed $(\mathrm{O})$.

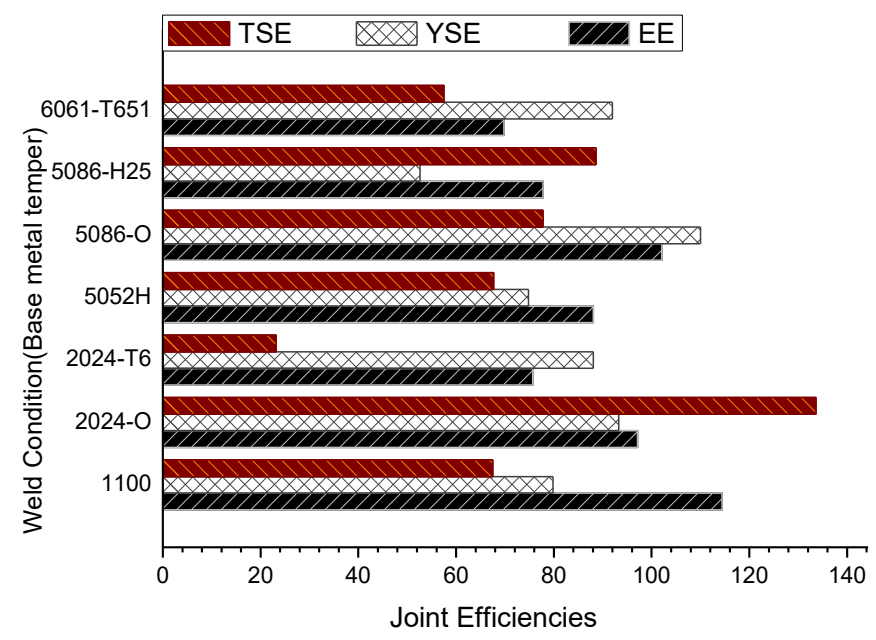

Figure 3. Different efficiencies of FSW joints

\section{FRACTOGRAPHY}

Failure of welds when aluminum alloy welded in soft annealed ' $O$ ' temper occurred away from the WNZ whereas hardened 'T6 and H' aluminum alloys welds fractured from WNZ. 
fracture occurred from HAZ on advancing side for AA1100-O and on retreating side for AA5086-O weld joints of work hardening alloys. Weld joints of precipitation hardening alloys AA2024-O broken from advancing side of base material. Same fracture locations were reported by Feng et al., 2006 in case of AA2219-O FSW welded joints. AA5052-H weld joints failed from WNZ toward the retreating side. Weld joints of AA2024-T6 fractured from retreating side WNZ-TMAZ interface and the same can be credited to notable difference in internal microstructure between WNZ and TMAZ. Weld joints of AA6061-T651 fractured from advancing side in WNZ zone. Failure locations are similar to that of tensile test and hardness minima results of the welds. Appearance of fracture surface is cup and cone with $1100-\mathrm{O}$, inclined to loading axes less than $45^{\circ}$ for $2024-\mathrm{O}$, inclined at $45^{0}$ to loading axes for 5086-O, 5086-H-25, and 2024-T6, and perpendicular to loading axes with 5052-H, and 6061T651.
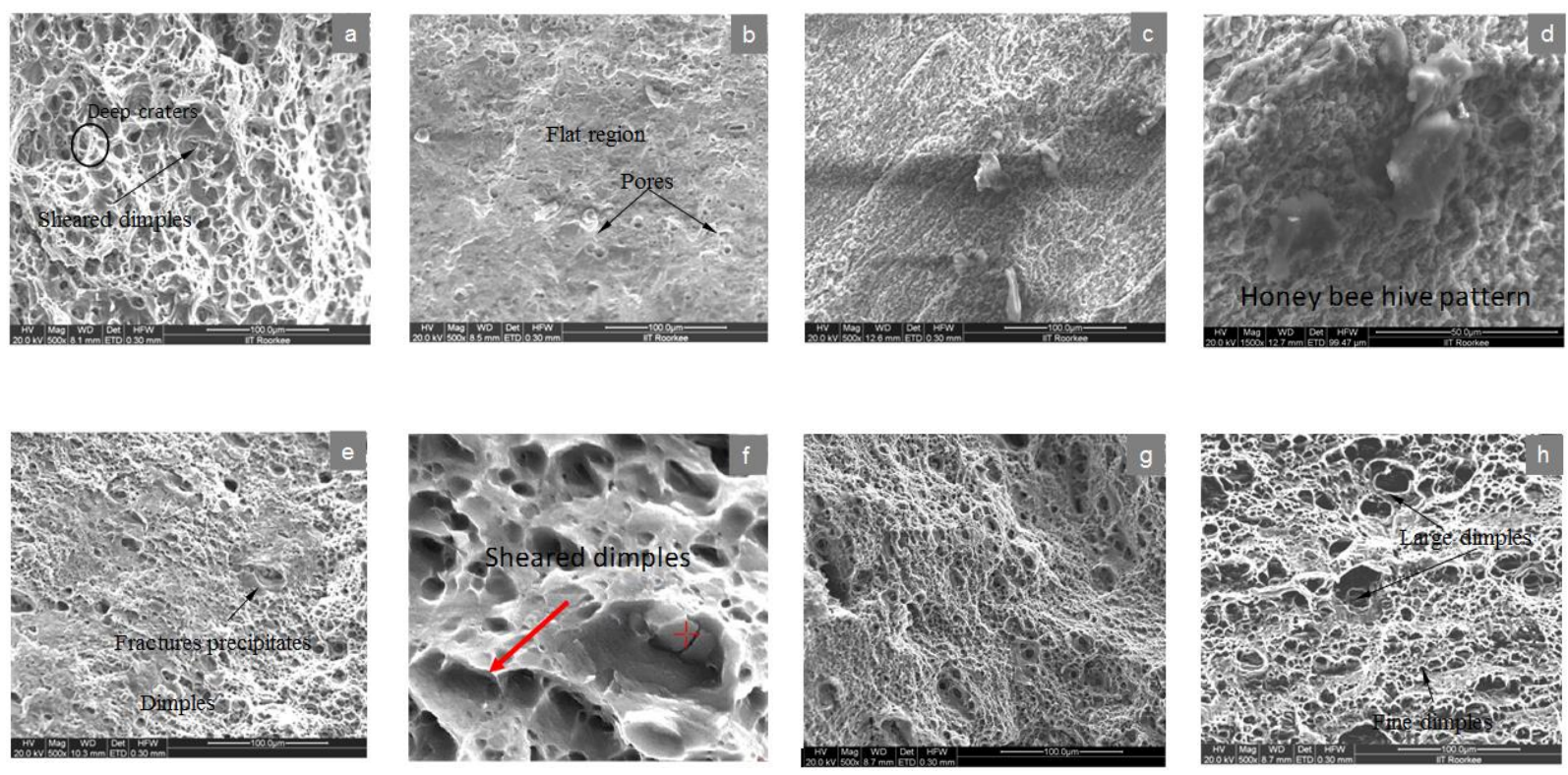

Figure 4. Fractographs showing fracture surfaces of FSW joints (a) AA1100O, (b) AA6061-T651, (c) AA2024-T6 (d) Enlarged view of AA2024-T6, (e) AA5086-O, (f) Enlarged view of AA5086-O, (g) AA5086-H25 and (h) AA5052-H

Fractographs obtained from weld fractured surface after tensile tests are presented in Fig. 4 (ah). Base metal temper has a significant effect on fracture mode. Fracture surfaces were flat 
and inclined to the loading axis for weld joints developed using AA1100-O, AA5052-H, and AA5086-O along with limited necking at the point of fracture. The fracture surface of AA2024-T6 weld joints showed waviness and similar to brittle failure with flat surface normal to loading axis. In the case of AA6061-T651 weld joints, fracture surfaces were flat and normal to tensile loading without any observable necking. A varying population of dimples was found on the fracture surface of all weld joints except for AA2024-T6, AA6061T651 as their fracture surfaces were relatively featureless. The fracture surface of the AA2024-O weld joint was covered with well-defined deep and large size dimples exhibiting ductile mode of fracture which is well supported by the highest joint elongation efficiency $(133.6 \%)$

Fracture surfaces of AA2024-T6 and AA6061-T651 joints mostly revealed flat featureless or layered featureless surfaces without dimples suggesting the lack of metallic bonding and material is in the ductile to the brittle transition phase. Honey bee hive pattern was also clearly visible showing very fine shallow dimples in higher magnification images shown in Fig 9 d. In case of AA6061-T651, few randomly distributed finer holes were also seen on the fracture surfaces. These findings are in good accordance with the comparatively low elongation efficiency of the AA2024-T6 (23.2\%) and AA6061-T651 (57.5\%) weld joints. The presence of course ' $\beta$ ' and ' $\theta$ ' phase precipitates (Fig. $6 \mathrm{~b}$ and c) resulted in the lowest elongation therefore brittle fracture. The fracture surfaces of AA1100-O and AA5052-H also showed deep and larger dimples with few thick tearing ridges, some traces of secondary deep dimples were also observed on the SEM images. The secondary deep dimples are formed due to the triaxial state of stress. These observations suggest a ductile fracture of these joints and findings are again in agreement with elongation efficiencies of joints ( 67.5\%). Deep craters were also visible on the fracture surface of AA-1100-O, formed due to tearing of material during fracture, and considered as a sign of higher ductility.

Fracture surface of AA5086-O exhibited mix presence of fine dimples, along with few featureless regions scattered randomly and visible pores. At higher magnification flat region 
also showed a network of finer dimples. Shallow dimples were observed during closer examination of flat regions, sheared off during failure of welded joints. Breaking of intermetallic/constituent particles (marked by ' + ' sign) to maintain the compatibility during tensile deformation, triggered the fracture and form voids which grew and coalesce.

Growth of voids reduces the resisting area of the cross-section to a value which can't support the applied tensile load further, therefore complete separation occurs. The red arrow indicates the direction of shearing of the dimples. Fracture mode was ductile for AA5086-H25 joints as dimples were present on fracture surface and have the second-highest elongation efficiency $(88.6 \%)$ because of loss of work hardening effect. The results indicate that peak hardened (T6) precipitation hardening aluminium alloys exhibit a brittle mode of fracture. Work hardening alloys in $\mathrm{O}$ or $\mathrm{H}$ temper condition exhibit ductile fracture mode along with precipitation hardening aluminium alloys in $\mathrm{O}$ temper condition.

\section{CONCLUSIONS}

The sound FSW joints developed to explore the consequence of base material type and temper on tensile and fracture behavior of work hardening and precipitation hardening aluminium alloys. Aluminium alloy type and temper condition have a great influence on the tensile, hardness and fracture behavior (i.e., location and mode) of FSW joints of solution and precipitation hardening aluminium alloys. Weld joints of solution and precipitation hardening aluminium alloys welded in hardened condition ( $\mathrm{H}$ and $\mathrm{T6}$ ) invariably exhibited a low hardness region while a reverse tendency was detected for weld joints made using base metal in annealed ' $\mathrm{O}$ ' condition. Base metal type does not find to influence the location of hardness minima, fracture location, and mode of fracture while its temper significantly affected the same. The hardness minima are found in the HAZ or base metal for weld joints in annealed ' $\mathrm{O}$ ' temper condition while that in hardened condition ' $\mathrm{H}$ and $\mathrm{T} 6$ ' lies in WNZ or WNZTMAZ interface. Fracture of welds took place from the hardness minima zone. Mode of fracture changed from ductile to brittle or mix mode fracture with the change of temper from annealed ' $\mathrm{O}$ ' to hardened condition ' $\mathrm{H}$ and $\mathrm{T} 6$ '. The thickness of base metal plates affects the 
selection of tool and process parameters as well as weld thermal cycle, tensile properties, and fracture of weld joints. The thick plates offered higher tensile strength and elongation than thin plates. Thin plates experienced severe softening and therefore fracture occurs from WNZ for thin plate welds. There is a need for further research to understand the role of base metal thickness on various aspects of FSW.

\section{REFERENCES}

Mandal, N.R., Aluminum welding. 1st ed. Delhi India: Narosa publishing house, 2005.

Hassan, A.A., Prangnell, P.B., Norman, A.F., Price, D.A. \& Williams, S.W. 2003. Effect of welding parameters on nugget zone microstructure and properties in high strength aluminum alloy friction stir welds. Sci Technol Weld Join, 8(4): 257-268.

Threadgill, P.L., Leonard, A.J., Shercliff, H.R., \& Withers, P.J. 2009. Friction stir welding of aluminum alloys. Int Mater Rev, 54(2): 49-93.

Guerra, M., Schmidt, C., McClure, J.C., Murr, L.E., \& Nunes, AC. 2003. Flow patterns during friction stir welding. Mater Charact, 49: 95-101.

Sato, Y.S., Hwan, S., Park, C., \& Kokawa, H. 2001. Microstructural factors governing hardness in FS welds of SS hardened Al alloy. Metall Mater Trans A, 32: 3033-3042.

Lim, S., Kim, S., Lee, C.G., \& Kim, S.J. 2005. Mechanical Properties of friction stir welded Al alloys with different hardening mechanisms. Met Mater Int, 11(2): 113-120.

Sharma, C., Dwivedi, D.K., \& Kumar, P. 2013. Effect of PWHTs on microstructure \& tensile properties of FSWed joints of Al-Zn-Mg AA7039. Mater Des, 43(1): 34-143.

Mahoney, M.W., Rhodes, C.G., Flintoff, J.G., Spurling, R.A., \& Bingel, W.H. 1998. Properties of FSWed 7075 T651 aluminum. Metall Mater Trans, 29: 1955-1964.

Sharma, C., et al. 2012. Effect of welding parameters on microstructure and mechanical properties of FSWed joints of AA7039 al alloy. Mater Des., 36: 379-390.

Peel, M., Steuwer, A., Preuss, M., \& Withers, P.J. 2003. Microstructure, mechanical properties and residual stresses as a function of welding speed in AA5083 friction stir welds. Acta Mater, 51(16): 4791-4801.

Sharma, C., Dwivedi, D.K., \& Kumar, P. 2014. Fatigue behavior of FS joints of Al-Zn-Mg alloy AA7039 using base metal in different temper. Mater Des, 64(12): 334-344. 
Uemastu, Y., Tokaji, K., Shibata, H., \& Ohmune, T. 2009. Fatigue behavior of FS Welds without neither welding flash nor flaw in several al alloys. Int J Fatigue, 31: 1443-1453.

Wadeson, D.A., Zhou, X., Thompson, G.E., Skeldon, P., Djapic, L., \& Scamans, G. 2006. Corrosion behavior of FSWed AA7108 T79 Al alloy. Corro Sci, 48: 887-897.

Jariyaboon, M. \& Williams, S.W., 2009. Price DA. Effect of cryogenic $\mathrm{CO}_{2}$ cooling on corrosion behavior of FSWed AA2024-T351. Corros Eng Sci Technol, 44(6): 425-432.

Sato, Y.S., Kokawa, H., Enmoto, M., Jogan, S. \& Hashimoto, T. 1999. Precipitation sequence in FSWeld of 6063 al during aging. Metall Mater Trans A, 30(12): 3125- 3130.

Liu, H.J., Fujii, H., Maedaa, M., \& Nogi, K. 2003a. Tensile properties\&fracture locations of FSWed joints of 2017-T351 al alloy. J Mater Process Technol 2003; 142: 692-696.

Liu, H.J., Fujii, H., Maeda, M., \& Nogi, K. 2003b. Mechanical properties of friction welded joints of 1050-H24 aluminum alloy. Sci Technol Weld Join, 8(6): 450-454.

Srivatsan T.S., Vasudevan S., \& Park L. 2007. The tensile deformation and fracture behavior of friction stir welded aluminum alloy 2024. Mater Sci Eng A, 466: 235-245.

Strombeck A.V., Santos J.F.D., Torster F., Laureano P., \& Kocak M. 1999. Proc. of 1st Int Friction Stir Welding Symposium California USA., TWI paper no. S9-P1.

Henz B., and Sarotzki. 2002. Characterization of a friction-stir-welded aluminum alloy 6013. Metall Mater Trans B, 33(3): 489-498.

Yan J. \& Reynolds A.P. 2009. Effect of initial base metal temper on mechanical properties in AA7050 friction stir welds. Sci Technol Weld Join, 14(4): 282-287.

Chen Y., Liu H., \& Feng J. 2006. Friction stir welding characteristics of different heat treated state 2219 aluminum alloy plates. Mater Sci Eng A, 420: 21-25.

Aydin H., Bayram A., Uguz A., \& Akay K.S. 2009. Tensile properties of FSWed joints of 2024 aluminum alloys in different heat treated state. Mater Des, 30: 2211-2221.

Liu H.J., Chen Y.C., \& Feng J.C. 2006. Effect of heat treatment on tensile properties of FSWed joints of 2219-T 6 aluminum alloy. Mater Sci. Technol., 22(2): 237-241.

Feng J.C., Chen Y.C., \& Liu H.J. 2006. Effect of PWHT on microstructure \&mechanical properties of FSWed joints of 2219-O al alloy. Mater Sci. Technol. 22(1): 86-90.

Lin H., Wu Y., \& Liu S. 2018. Impact of initial temper of base metal on microstructure and mechanical properties of FSWed AA 7055 alloy. Mat Char, 146, 159-168. 
Zhao T., Sato Y.S., \& Kokawa H. 2020. Predicting Tensile Properties of FSWed 6063 Al with Experimentally Measured Welding Heat Input. Acta Metall. Sin., 33, 1235-1242.

Hamilton C., Dymek S., \& Pietras A. 2018. Numerically Based Phase Transformation Maps for Dissimilar Aluminum Alloys Joined by FSW. Metals, 8(5), 324. 